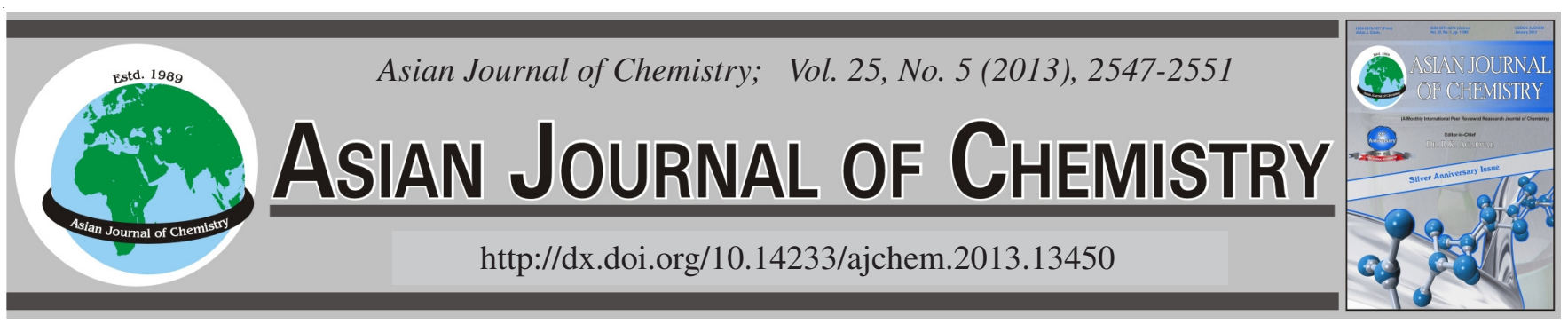

\title{
Electron-Transfer Reaction of Cytochrome c Adsorbed on Mixed Alkanethiol Monolayer Electrode and Its Electrocatalytic Activity
}

\author{
Yu Wang, Lingli Wan, Yonghai Song* and Li WANG
}

College of Chemistry and Chemical Engineering, Jiangxi Normal University, Nanchang 330022, P.R. China

*Corresponding author: Tel/Fax: +86 791 8120861; E-mail: yhsong@jxnu.edu.cn

\begin{abstract}
The electron-transfer kinetics of cytochrome c (cyt. c) immobilized on self-assembled monolayers modified gold electrode was demonstrated. Mixed monolayer films of 6-mercapto-1-hexanol and 11-mercaptoundecanoic acid are used to adsorb cytochrome c on the surface of gold electrode. These adsorbed cytochrome c molecules remained a dilute concentration on the mixed films. Electrochemical method and scanning tunneling microscopy technique was used to study the adsorbed protein. It showed a surface-controlled electrode process with the electron transfer rate constant of $65 \mathrm{~s}^{-1}$. The adsorbed cytochrome c maintained its activity and could also electrocatalyze the reduction of hydrogen peroxide, the $\mathrm{K}_{\mathrm{m}}{ }^{\text {app }}$ for this sensor was found to be $3.41 \mathrm{mM}$.
\end{abstract}

Key Words: Cytochrome c, Self-assembled monolayers, Direct electrochemistry, Electrocatalyze.

\section{INTRODUCTION}

The preparation and characterization of electrode-bound redox protein monolayers is important for bioelectrocatalytic applications such as amperometric biosensors as well as for the field of biological electron transfer (ET). The immobilization of redox enzyme monolayers for bioelectrocatalytic purposes dates back more than two decades ${ }^{1}$, with the major goal being to realize selective catalysis for biosynthesis or biosensing applications. Recent studies have described a number of new amperometric biosensor configurations based on the concept of monolayer electrochemistry ${ }^{2}$.

Horse heart cytochrome c (cyt. c), a relatively simple metalloprotein comprising only 104 amino acids, is often used as the prototypical metalloprotein from a structural point of view $^{3}$. However, its electrochemical studies have been hampered because it adsorbs strongly on $\mathrm{Au}, \mathrm{Ag}, \mathrm{Hg}, \mathrm{Pt}$ and other solid electrodes. This adsorption has resulted in large changes in its conformation and often in denaturation of the protein ${ }^{4-6}$. Efforts to limit denaturing adsorption have led to the use of several biocompatible surface self-assembled monolayers $(\mathrm{SAMs})^{7-9}$, especially the alkanethiolate/gold self-assembled monolayers to modify the electrode surface for preparing stable cytochrome $\mathrm{c}$ monolayers $^{3}$. Previous works ${ }^{10-18}$ have immobilized cytochrome c by electrostatic association of carboxylic acid-terminated alkanethiol monolayer films with the positively charged outer surface of the protein. These systems allow for the implementation of well-defined electrochemistry and electron transfer rate constant measurements as a function of the film thickness. Most recently, cytochrome $\mathrm{c}$ was immobilized on the surface of pure and mixed monolayers of pyridine-terminated alkanethiols that had alkane chain lengths of more than six methylenes to realize the direct electron transfer ${ }^{19,20}$.

In this work, mixed monolayer film was used to associate with a specific part of cytochrome $\mathrm{c}$ and promote electron transfer to its redox center. With the use of mixed films of 6-mercapto-1-hexanol and 11-mercaptoundecanoic acid, cytochrome c was immobilized on the SAMs surface through association of the - $\mathrm{COOH}$ with the heme group. Electrochemical measurements and STM imaging were both used to demonstrate the immobilization of the protein on the surfaces. The adsorbed cytochrome $\mathrm{c}$ maintained its activity and could also electrocatalyze the reduction of hydrogen peroxide.

\section{EXPERIMENTAL}

Horse heart cytochrome c (cyt. c) was obtained from Sigma. 6-Mercapto-1-hexanol (MHA) and 11-mercaptoundecanoic acid (MUDA) were obtained from Aldrich. A 30 $\%$ hydrogen peroxide solution was purchased from Beijing Chemical Reagent (Beijing, China) and a fresh solution of $\mathrm{H}_{2} \mathrm{O}_{2}$ was prepared daily. All other chemicals were of analytical grade and were used as received. Pure water was used throughout, which was obtained using a Millipore Q water purification apparatus.

Preparation of the electrode: A bulk gold disk electrode was constructed using gold wire $(99.99 \%, 1.0 \mathrm{~mm}$ diameter $)$ 
in a soft glass tube. It was polished carefully with 1.0-, 0.3and $0.05 \mu \mathrm{m}$ alumina slurry and sonicated in water and absolute ethanol. Prior to the experiment, the bare gold electrode $(\mathrm{Au})$ was scanned by cyclic voltammetry within the potential range of 1.5 to $-0.2 \mathrm{~V}$ in freshly prepared deoxygenated $0.5 \mathrm{M} \mathrm{H}_{2} \mathrm{SO}_{4}$ until a voltammogram characteristic of the clean polycrystalline gold electrode was established ${ }^{21}$. The true area of the gold electrode was $0.021 \mathrm{~cm}^{2}$, determined by integration of the cathodic peak for the reduction of the gold oxide layer in $0.5 \mathrm{M}$ $\mathrm{H}_{2} \mathrm{SO}_{4}$. The cleaned electrode was thoroughly rinsed with water and absolute ethanol and was immersed in an ethanol solution that contained $1 \mathrm{mM}$ MHA and $1 \mathrm{mM}$ MUDA. The electrode remained in this solution for $24 \mathrm{~h}$ to form the mixed SAM. The electrode was taken out from the solution, first rinsed with absolute ethanol, then rinsed with the supporting buffer solution (10 mM phosphate buffer $\mathrm{pH} 7.0)$ and finally dried by a stream of dry argon gas. Then the electrode was immersed in a $1 \mathrm{mM}$ cyt. c solution (purged with argon gas) for 30-60 min in order to immobilize the cyt. c on the SAM-coated electrode. These electrodes were immediately used in electrochemical studies.

Electrochemistry experiments: All the electrochemical measurements were carried out with an Autolab PGSTAT30 electrochemical analyzer system (Eco Chemie B.V. Utrecht, Netherlands). All experiments were carried out using a conventional three-electrode system with the SAM-coated Au electrode as the working electrode, a platinum wire as the auxiliary electrode and an $\mathrm{Ag} / \mathrm{AgCl}$ (saturated $\mathrm{KCl}$ ) electrode as the reference electrode. Cyclic voltammetric experiments were performed in quiescent solution. Electrolyte solutions were purged with high-purity nitrogen and under nitrogen atmosphere during electrochemical experiments. Voltammograms of the first scan were shown in all figures and the measurements were carried out at $23{ }^{\circ} \mathrm{C}$.

STM Measurements: $\mathrm{A} \mathrm{Au}(111)$ facet of a single crystalline bead prepared by Clavilier's method ${ }^{22}$ was used as the substrate for all STM studies. The bead was cleaned by immersion in hot piranha solution for $1 \mathrm{~h}$ and in hot $\mathrm{HNO}_{3}$ for $0.5 \mathrm{~h}$. Then the sample was rinsed by ultrasonication in ultrapure water. The bead was hydrogen flame annealed and cooled to room temperature. The preparation of mixed SAMs of MHA and MUDA on the Au (111) bead for STM was the same as the SAMs prepared for electrochemical experiments. Two beads were put into the mixture for $24 \mathrm{~h}$. One bead was rinsed with ethanol and then directly used for STM experiments and the other bead was placed in a solution of cyt. c for 30-60 min to immobilize the protein. After rinsed with supporting buffer, this bead was immediately analyzed by STM. The STM images were obtained using a Digital Instruments Nanoscope IIIa (Santa Barbara, CA). STM tips were electrochemically etched tungsten tips. All STM images were raw data except for flattening. All of the STM images were obtained under constant current mode at 5-15 pA and a tipsample bias of 0.2-0.5 V under the ambient conditions.

\section{RESULTS AND DISCUSSION}

Cyclic voltammetry of an electroactive species such as $\mathrm{Fe}(\mathrm{CN})_{6}^{4-/ 3-}$ is a valuable tool for testing the kinetic barrier of the interface because the electron transfer between a solution species and the electrode must occur by tunneling either through the barrier or through the defects in the barrier ${ }^{23}$. Fig. 1 illustrates the blocking behaviour of $5 \mathrm{mM} \mathrm{Fe}(\mathrm{CN})_{6}^{3-14-}$ observed for the differently modified electrode. At the bare gold electrode, the well-defined shape of the cyclic voltammogram and the $70 \mathrm{mV}$ peak separation indicate a diffusion-limited or electrochemically quasi-reversible one-electron redox process $^{24}$. In contrast, the voltammogram for the MHA and MUDA films (Au/SAMs) is markedly different and shows the common blocking behaviour for insulating alkanethiol modified electrodes ${ }^{23,25}$. The blocking behaviour indicates that the SAMs are well-packed and inhibit penetration of $\mathrm{Fe}(\mathrm{CN})_{6}^{3-44}$. After cyt. c has adsorbed on the SAMs, only very weak influence of defect sites on the observed faradaic current was observed on the resulted electrode ( $\mathrm{Au} / \mathrm{SAMs} / \mathrm{cyt}$. c). It might be due to the much smaller size of $\mathrm{Fe}(\mathrm{CN})_{6}{ }^{3-14-}$ probe as compared to a cyt. c molecule.

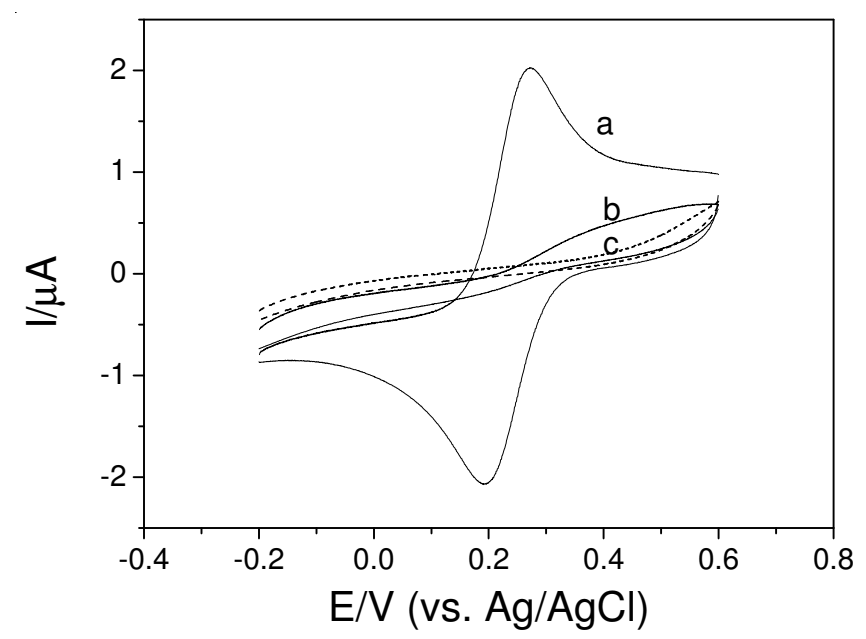

Fig. 1. Cyclovoltametric graphs of (a) bare gold electrode (Au), (b) SAMs modified gold electrode and (c) cyt. c modified electrode. Supporting electrolyte: $5 \mathrm{mM} \mathrm{Fe}(\mathrm{CN})_{6}{ }^{3-4-}+0.5 \mathrm{M} \mathrm{KCl}$ and scan rate: $50 \mathrm{mV} \mathrm{s}^{-1}$

Fig. 2 shows the results of impendance spectroscopy on bare $\mathrm{Au}, \mathrm{Au} / \mathrm{SAMs}$ and $\mathrm{Au} / \mathrm{SAM} /$ cyt. c electrodes in the presence of equimolar $\mathrm{Fe}(\mathrm{CN})_{6}^{3-/ 4-}$. To give more detailed information about the electrical properties of both the $\mathrm{Au} /$ solution and the $\mathrm{Au} / \mathrm{SAMs} /$ solution interfaces, the Randles circuit (inset of Fig. 2) was chosen to fit the impedance data $a^{21,24,26}$. In the Randles circuit, the resistance to charge transfer $\left(\mathrm{R}_{\mathrm{ct}}\right)$ and the diffusion impedance $(\mathrm{W})$ were both assumed in parallel to the interfacial capacity $\left(\mathrm{C}_{\mathrm{dl}}\right)$. This parallel structure of $\mathrm{R}_{\mathrm{ct}}$ and $\mathrm{C}_{\mathrm{dl}}$ gave rise to a semicircle in the complex plane plot of $Z_{\text {im }}$ against $Z_{\text {re. }}$ Fig. 2a shows the impedance spectrum of the bare gold electrode. The calculated $\mathrm{R}_{\mathrm{ct}}$ for the $\mathrm{Fe}(\mathrm{CN})_{6}^{3-14-}$ redox couple was $38.6 \mathrm{~W} \mathrm{~cm}^{2}$. The results for the $\mathrm{Au} / \mathrm{SAMs}$ and $\mathrm{Au} / \mathrm{SAMs} / \mathrm{cyt}$. c electrode in the presence of the electrontransfer reaction were shown in Fig. $2 b-c . R_{c t}$ were increased to 17.07 and $68.04 \mathrm{~K} \Omega \mathrm{cm}^{2}$ on the $\mathrm{Au} / \mathrm{SAMs}$ and $\mathrm{Au} / \mathrm{SAMs} /$ cyt. c electrode, respectively. These data showed that the SAMs and cyt. c molecules were successfully assembled on the gold electrode surface and inhibited electron transfer, which were consistent with the cyclic voltammetry results. 


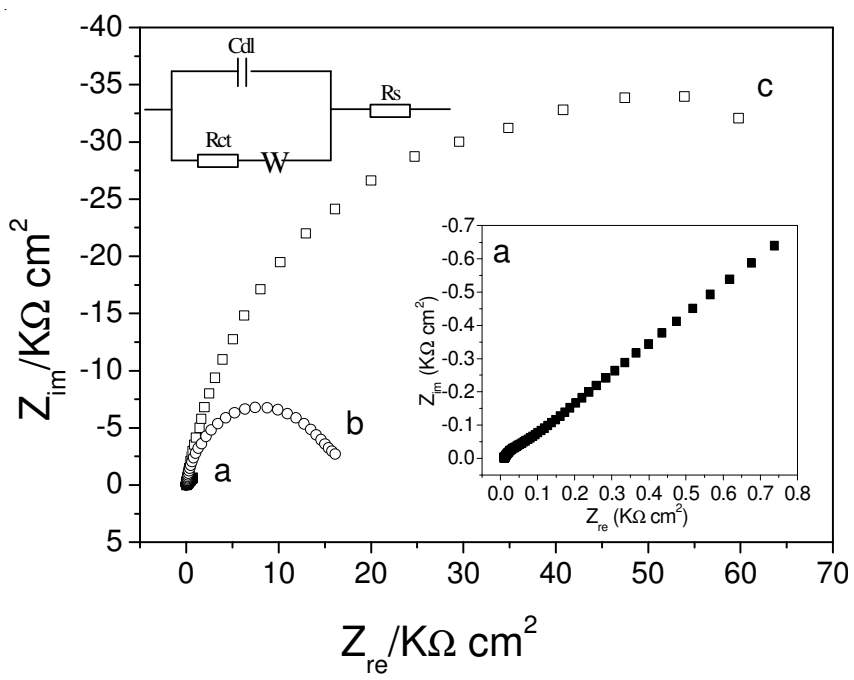

Fig. 2. Impendence plots of (a) Au, (b) Au/SAMs and (c) Au/SAMs/cyt. c electrodes in the presence of $5 \mathrm{mM} \mathrm{Fe}\left(\mathrm{CN}_{6}{ }^{3-14}\right.$ with $0.1 \mathrm{M} \mathrm{KCl}$ as the supporting electrolyte. The electrode potential was $0.23 \mathrm{~V} v s$. $\mathrm{Ag} / \mathrm{AgCl} / \mathrm{KCl}$ and the frenquency range was $0.1 \mathrm{~Hz}$ to $100 \mathrm{KHz}$. Inset is the Randles circuit

STM characterization: STM measurements were also used to characterize the films. Fig. 3 shows STM images of the SAMs systems both with and without incubating the electrode in the cyt. c solution. Fig. 3a shows image of the mixed monolayer film. There were dark regions with diameter of 20-30 A. Such structures have been always reported for alkanethiol films modified gold electrodes ${ }^{27}$. Fig. $3 b$ shows images of the monolayer film immobilized with protein. Cyt. c molecules appeared as bright spots that were absent before the adsorption. The height of the spots was $1.1 \pm 0.2 \mathrm{~nm}$. The average size of a spot was $4.5 \pm 1.0 \mathrm{~nm}$ in diameter. The size and height of the spots are both similar to a cyt. c molecule ${ }^{28}$ and consistent with the previous results of STM images of cyt. $c^{20,29,30}$. It can be observed readily in the image that the distribution of cyt. $c$ on the surface is not uniform; the protein distributed with higher density in some domains and with lower density in other domains.

Electrochemistry of cytochrome c adsorbed electrode: Fig. 4 shows voltammograms of the SAMs coated gold electrode and the same electrode after incubating in the cyt. c solution. When the SAMs-coated electrode was placed directly in the buffer solution, no faradaic response was observed in the voltammogram. After the same electrode was modified with cyt. c and placed in the buffer solution, a well-defined faradic response was observed. The formal redox potential for the ferri/ferro-cyt. c couple, measured in neutral solution of $\mathrm{pH} 7.0$, is $0.07 \mathrm{~V}$ versus $\mathrm{Ag} / \mathrm{AgCl}$ and changes with temperature $^{31,32}$, pressure ${ }^{33,34}$, electrolyte composition and ionic strength $^{34,35}$. In this work, the redox potential of cyt. c was ca. $0.01 \mathrm{~V}$, which was $0.06 \mathrm{~V}$ lower than the formal redox potential. For it is widely believed that at this potential the negatively charged carboxyl-terminated SAMs cause the lysine-rich, positively charged (at neutral $\mathrm{pH}$ ) cyt. c to adsorb on the surface with a relatively unperturbed structure and to adopt an orientation with respect to the electrode that permits rapid electron exchange $\mathrm{e}^{3,36}$.
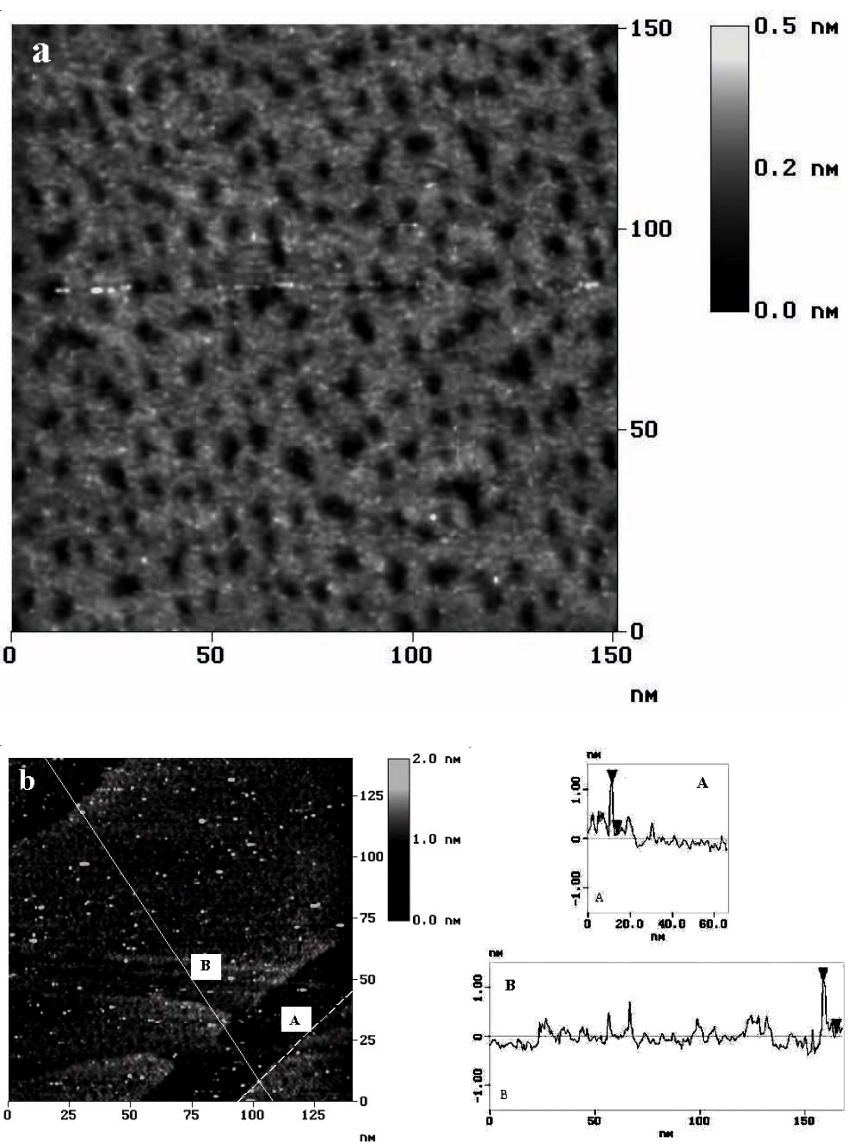

Fig. 3. (a) Topographic STM images of SAMs modified gold substrate and (b) cyt. c modified Au/SAMs surface. Cross section analysis of one cyt c molecule from two different directions was shown in (b). The bias is $0.3 \mathrm{~V}$ and the current set point is $5 \mathrm{pA}$

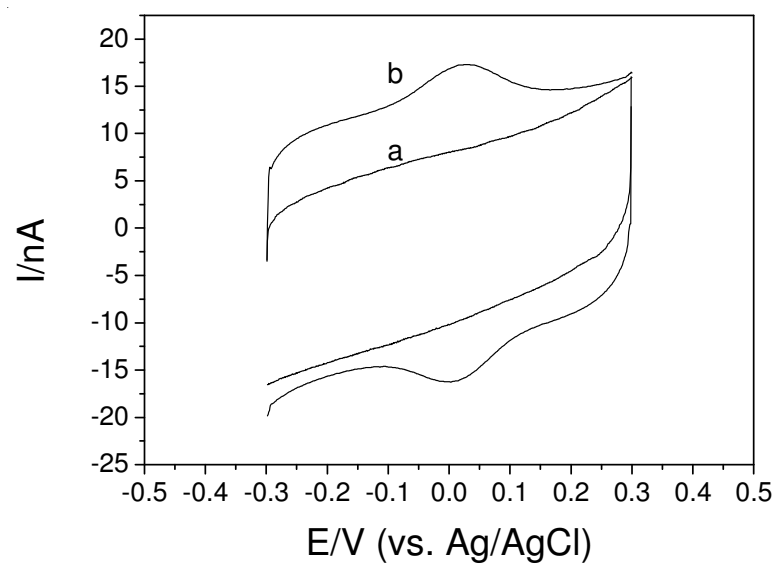

Fig. 4. Cyclovoltammograms of Au/SAMs (a) and Au/SAMs/Cyt c (b) in $20 \mathrm{mM}, \mathrm{pH}$ 7.0 PBS. Scan rate, $50 \mathrm{mV} \mathrm{s}^{-1}$

The peak current of the electrode adsorbed with cyt. c was measured as a function of the voltage scan rate, as shown in Fig. 5. The inset of Fig. 5 showed the linear relation between $\log i_{\mathrm{pc}}$ and $\log \mathrm{v}$. The slope of it is 0.95 , because the slope is 1 for the ideal thin layer electrochemistry ${ }^{37}$. Thus it is consistent with immobilization of the cyt. c on the surface. When a redox couple is immobilized on the electrode surface, the surface coverage could be determined by integrating the oxidation and reduction peaks of the voltammograms. The surface coverage of cyt. c was calculated to be $2.85 \pm 0.25 \times$ 


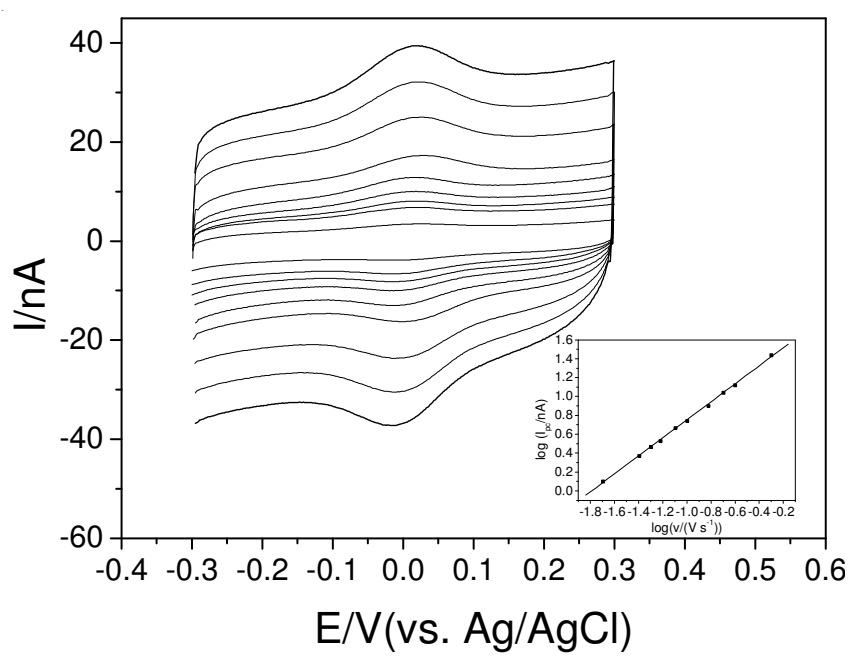

Fig. 5. CVs of Au/SAMs/cyt c in $20 \mathrm{mM}$, pH 7.0 PBS at 20, 40, 50, 60, 80, $100,150,200,250 \mathrm{mV} \mathrm{s}^{-1}$ (from lowest to highest peak currents). The insert showed the linear relationship of logarithm of cathodic peak currents $\left(\mathrm{I}_{\mathrm{p}}\right) v s$. logarithm of scan rate $(\mathrm{v})$ for Au/SAMs/cyt c electrode

$10^{-12} \mathrm{~mol} \mathrm{~cm}^{-2}$ with this method. The surface coverage of cyt. c could also be calculated from the relationship between the peak current $\left(i_{p}\right)$ and the surface coverage $(\Gamma)$ as shown below $^{24}$ :

$$
\mathrm{i}_{\mathrm{p}}=\frac{\mathrm{n}^{2} \mathrm{~F}^{2}}{4 \mathrm{RT}} \mathrm{vA} \Gamma
$$

In the formula, $\mathrm{n}$ is the number of electrons transferred ( $n=1$ here), $\mathrm{F}$ is Faraday's constant, $\mathrm{v}$ is the voltage scan rate and $\mathrm{A}$ is the electrode area. With the slope of $\mathrm{i}_{\mathrm{p}}$ versus $\mathrm{v}$ plot, the surface coverage of cyt. $c$ was calculated to be $2.80 \pm 0.12$ $\times 10^{-12} \mathrm{~mol} \mathrm{~cm}^{-2}$. The coverage data calculated from these two methods were quite consistent. The dependence of the difference between reduction and oxidation peak position on the voltage scan rate can be used to characterize the electrontransfer rate constant $t^{38,39}$. This method was used to determine rate constants for cyt. c immobilized films. Fig. 6 shows a plot of the anodic-to-cathodic peak separations as a function of the logarithm of the voltammetric scan rate fot cyt. c adsorbed on the mixed SAMs. We estimate the electron-transfer rate constant $\mathrm{k}^{0}$ to be $65 \mathrm{~s}^{-1}$ after the model of Laviron ${ }^{40}$. It was consistent with electron transfer of cyt. c coupled to other w-terminated alkanethiol SAMs ${ }^{36}$. The persistence of the cyt. c voltammetric signal was addressed by the data in Fig. 7 . Cyt. c immobilized on the SAMs is so stable that the peak current had no obvious decrease after continuously scanning 20 circles at $0.05 \mathrm{~V} \mathrm{~s}^{-1}$.

Electrocatalysis of adsorbed cytochrome $c$ to the reduction of hydrogen peroxide: The resulted $\mathrm{Au} / \mathrm{SAMs} / \mathrm{cyt}$. c electrode also displayed an electrochemical response to hydrogen peroxide due to the presence of the cytochrome heme (Fig. 8). Such electrocatalytic behaviour has been observed in previous works, such as the incorporated cyt. c in the clay ${ }^{8}$ and the cyt. c adsorbed on colloidal gold modified electrode ${ }^{9}$. An obvious enhancement in the reduction current and decrease in the oxidation current could be observed in the presence of $0.5 \mathrm{mM} \mathrm{H}_{2} \mathrm{O}_{2}$ (Fig. 8). This illustrates that the resulted electrode can catalyze the reduction of $\mathrm{H}_{2} \mathrm{O}_{2}$ efficiently. At the

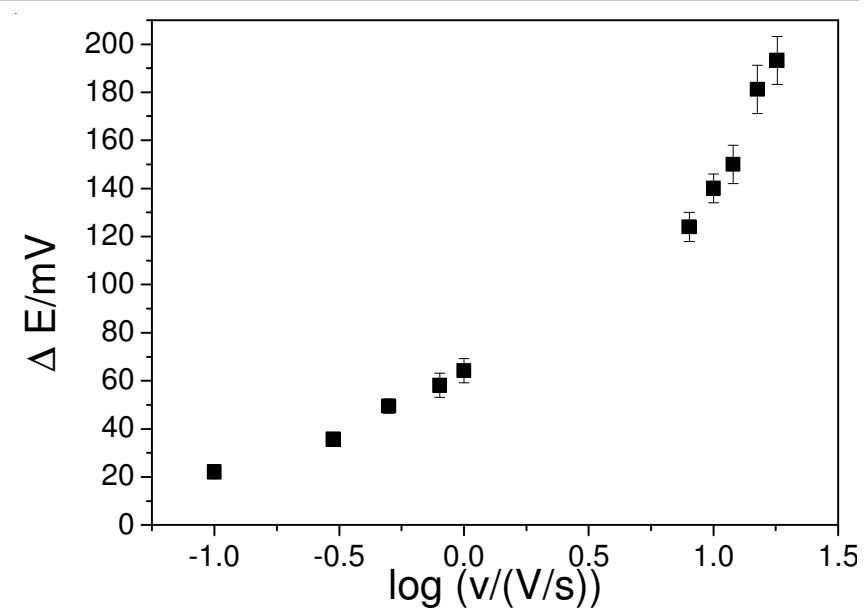

Fig. 6. Plots of the anodic-to-cathodic peak separations as a function of the logarithmic of scan rate. The experimentsal conditions are the same as in Fig. 5

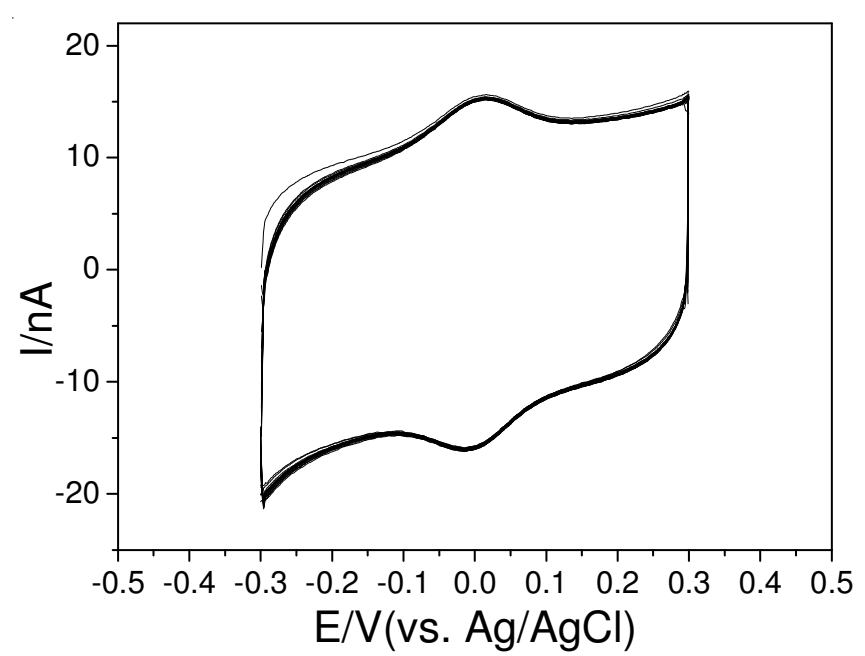

Fig. 7. Reproducibility of the Au/SAMs/cyt c in $20 \mathrm{mM}$, pH 7.0 PBS. Scans $1-20$

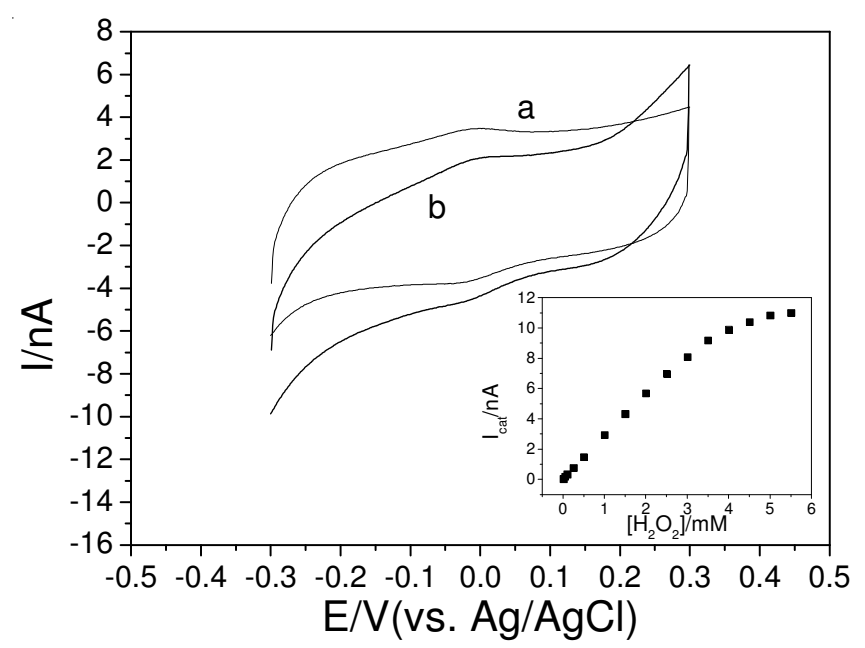

Fig. 8. CVs of cyt c immobilized on Au/SAMs electrode in $0.1 \mathrm{M} \mathrm{pH} 7.0$ PBS without $\mathrm{H}_{2} \mathrm{O}_{2}$ (a) and with $0.5 \mathrm{mM} \mathrm{H}_{2} \mathrm{O}_{2}$ (b) at $10 \mathrm{mV} / \mathrm{s}$. Inset: plots of electrocatalytic currents vs. $\mathrm{H}_{2} \mathrm{O}_{2}$ concentrations at $0 \mathrm{mV}$

same potential of $0.0 \mathrm{mV}$, there were $1.1 \mathrm{nA}$ increase in the cathodic current with and without addition of $0.5 \mathrm{mM} \mathrm{H}_{2} \mathrm{O}_{2}$. The increase can be considered as the electrocatalytic current. The calibration curve of the biosensor is shown in the inset of 
Fig. 8. The linear range of $\mathrm{H}_{2} \mathrm{O}_{2}$ concentration spans between $10 \mu \mathrm{M}$ to $2.0 \mathrm{mM}$ with a correlation coefficient of 0.9993 . The reproducibility of the sensor was examined at a $\mathrm{H}_{2} \mathrm{O}_{2}$ concentration of $1.0 \mathrm{mM}$ with the same electrode and the relative standard deviation was $3.6 \%$ for five successive assays.

The voltammetric response displayed the characteristics of the Michaelis-Menten mechanism according to the further increased $\mathrm{H}_{2} \mathrm{O}_{2}$ concentration. With the use of the electrochemical version of the Lineweaver-Burk equation ${ }^{41}$, the apparent Michaelis-Menten constant, $\mathrm{K}_{\mathrm{m}}{ }^{\text {app }}$, was found to be $3.41 \mathrm{mM}$ for adsorbed cyt. c (Fig. 9). And $\mathrm{K}_{\mathrm{m}}{ }^{\text {app }}$ is a measure of the affinity of an enzyme for its substrate. This value was lower than that of free horseradish peroxidase $(11 \mathrm{mM})$ and immobilized horseradish peroxide by sol-gel $(4.8 \mathrm{mM})^{42}$, which indicated that the present cyt. c modified gold electrode exhibited a comparably high affinity for $\mathrm{H}_{2} \mathrm{O}_{2}$.

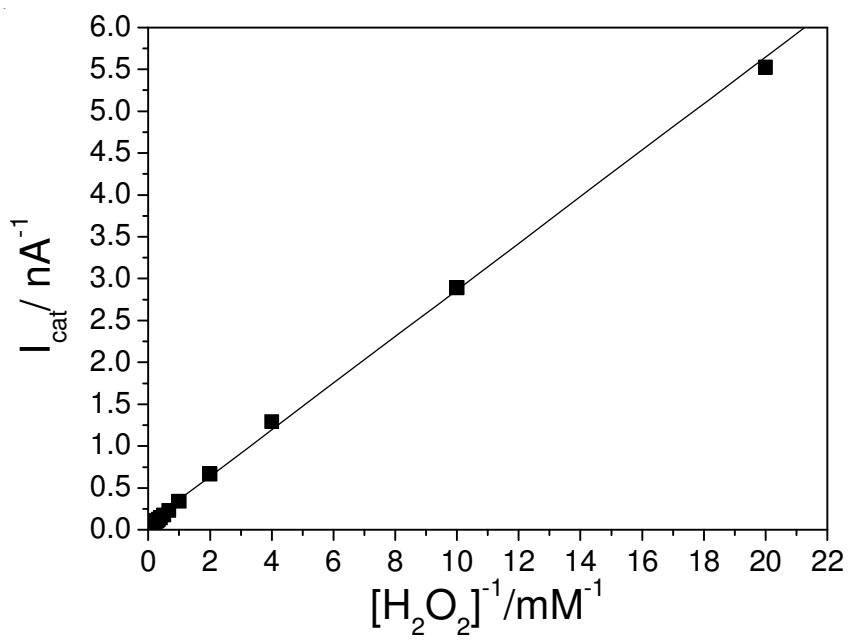

Fig. 9. Data analysis of electrocatalytic current for Michaelis-Menten

\section{Conclusion}

Mixed SAMs films of 6-mercapto-1-hexanol and 11mercaptoundecanoic acid were used to adsorb the cytochrome $\mathrm{c}$ on a gold electrode. Cytochrome $\mathrm{c}$ was immobilized onto electrode surfaces through the interaction of the - $\mathrm{COOH}$ group with the heme of the cytochrome. Electrochemistry and STM were used to observe the adsorption of the cyt. c on the surface of the monolayer film. Finally, the electron-transfer rate constant for the cyt. c adsorbed on the film's surface was measured and found to be $65 \mathrm{~s}^{-1}$. The adsorbed cyt. c maintained its activity and could also electrocatalyze the reduction of hydrogen peroxide. The system provides an alternative route to study direct electrochemistry of proteins and prepare hydrogen peroxide sensors.

\section{ACKNOWLEDGEMENTS}

This work was financially supported by National Natural Science Foundation of China (20905032, 21065005), Young Scientist Foundation of Jiangxi Province (20112BCB23006), Foundation of Jiangxi Educational Committee (GJJ10389), the State Key Laboratory of Electroanalytical Chemistry (2008003) and the Scientific Research Foundation for the Returned Overseas Chinese Scholars, State Education Ministry.

\section{REFERENCES}

1. S.D. Varfolomeev and I.V. Berezin, Abstracts of Paper, Advances in Physical Chemistry: Current Developments in Electrochemistry and Corrosion, Moscow: MIR, p. 60 (1982).

2. N.K. Chaki and K. Vijayamohanan, Biosens. Bioelectron., 17, 1 (2002).

3. M. Fedurco, Coord. Chem. Rev., 209, 263 (2000).

4. C. Hinnen, R. Parsons and K. Nikki, J. Electroanal. Chem., 147, 329 (1983).

5. D.E. Reed and F.M. Hawkridge, Anal. Chem., 59, 2334 (1987).

6. F.A. Armstrong, Struct. Bonding, 72, 137 (1990).

7. L. Wang and E.K. Wang, Electrochem. Commun., 6, 49 (2004).

8. C.H. Lei, F. Lisdat, U. Wollenberger and F.W. Scheller, Electroanal., 11, 274 (1999).

9. H. Ju, S. Liu, B. Ge, F. Lisdat and F.W. Scheller, Electroanal., 14, 141 (2002).

10. P.M. Allen, H.A.O. Hill and N.J. Walton, J. Electroanal. Chem., 178, 69 (1984).

11. G. McLendon, Acc. Chem. Res., 21, 160 (1988).

12. M.J. Tarlov and E.F. Bowden, J. Am. Chem. Soc., 113, 1847 (1991).

13. M. Collinson, E.F. Bowden and M.J. Tarlov, Langmuir, 8, 1247 (1992).

14 S. Song, R.A. Clark, E.F. Bowden and M.J. Tarlov, J. Phys. Chem. B, 97, 6564 (1993).

15. Z.Q. Feng, S. Imabayashi, T. Kakiuchi and K.J. Niki, J. Chem. Soc. Faraday Trans., 93, 1367 (1997).

16. A.E. Kasmi, J.M. Wallace, E.F. Bowden, S.M. Binet and R.J. Linderman, J. Am. Chem. Soc., 120, 225 (1998).

17. A. Avilla, B.W. Gregory, K. Niki and T.M. Cotton, J. Phys. Chem. B, 104, 2759 (2000).

18. L. Wang and D.H. Waldeck, J. Phys. Chem. C, 112, 1351 (2008).

19. H. Yamamoto, H. Liu and D.H. Waldeck, Chem. Commun., 1032 (2001).

20. J. Wei, H. Liu, A.R. Dick, H. Yamamoto, Y. He and D.H. Waideck, J. Am. Chem. Soc., 124, 9591 (2002).

21. E. Sabatani, I. Rubinstein, R. Maoz and J. Sagiv, J. Electroanal. Chem., 219, 365 (1987).

22. J. Clavilier, R. Faure, G. Guinet and R. Durand, J. Electroanal. Chem., 107, 205 (1980).

23. H.O. Finklea, Electroanalytical Chemistry, New York: Marcel Dekker (1996).

24. A.J. Bard and L.R. Faulkner, Electrochemical Methods: Fundamentals and Applications, New York: Wiley (1980).

25. C.J. Miller, Physical Electrochemistry: Principles, Methods and Applications, New York: Marcel Dekker, p. 27 (1995).

26. H.O. Finklea, D.A. Snider, J. Fedyk, E. Sabatani, Y. Gafni and I. Rubinstein, Langmuir, 9, 3660 (1993).

27. G.E. Poirier, Chem. Rev., 97, 1117 (1997).

28. R.A. Scott, Cytochrome C: A Multidisciplinary Approach, Sausalito (1996).

29. J.E.T. Anderson, P. Møller, M.V. Pedersen and J. Ulstrup, Surf. Sci., 325, 193 (1995).

30. D. Hobara, S. Imabayashi and T. Kakiuchi, Nano Lett., 2, 1021 (2002).

31. X.L. Yuan, F.M. Hawkridge and J.F. Chlebowski, J. Electroanal. Chem., 350, 29 (1993).

32. G. Battistuzzi, M. Borsari, M. Sola and F. Francia, Biochemistry, 36, 16247 (1997).

33. J. Sun, J.F. Wishart, R.V. Eldik, R.D. Shalderes and T.W. Swaddle, J. Am. Chem. Soc., 117, 2600 (1995).

34. H. Allen, O. Hill, N.I. Hunt and A.M. Bond, J. Electroanal. Chem., 436, 17 (1997).

35. A. Szucs and M. Novak, J. Electroanal. Chem., 383, 75 (1995).

36. X. Chen, R. Ferrigno, J. Yang and G.M. Whitesides, Langmuir, 18, 7009 (2002).

37. R.W. Murray, Electroanalytical Chemistry, New York: Marcel Dekker, p. 191 (1984).

38. L. Tender, M.T. Carter and R.W. Murray, Anal. Chem., 66, 3173 (1994).

39. K. Weber and S.E. Creager, Anal. Chem., 66, 3164 (1994).

40. E. Laviron, J. Electroanal. Chem., 101, 19 (1979).

41. R.A. Kamin and G.S. Willson, Anal. Chem., 52, 1198 (1980).

42. J. Li, S.N. Tan and H. Ge, Anal. Chim. Acta, 335, 137 (1996). 